\title{
Research
}

\section{Addressing the crisis of GP recruitment and retention:}

\author{
a systematic review
}

\begin{abstract}
Background

The numbers of GPs and training places in general practice are declining, and retaining GPs in their practices is an increasing problem.

\section{Aim}

To identify evidence on different approaches to retention and recruitment of GPS, such as intrinsic versus extrinsic motivational determinants.
\end{abstract}

\section{Design and setting}

Synthesis of qualitative and quantitative research using seven electronic databases from 1990 onwards (Medline, Embase, Cochrane Library, Health Management Information Consortium [HMIC], Cumulative Index to Nursing and Allied Health Literature (Cinahl), PsycINFO, and the Turning Research Into Practice [TRIP] database.

\section{Method}

A qualitative approach to reviewing the literature on recruitment and retention of GPs was used. The studies included were English-language studies from Organisation for Economic Cooperation and Development countries. The titles and abstracts of 138 articles were reviewed and analysed by the research team.

\section{Results}

Some of the most important determinants to increase recruitment in primary care were early exposure to primary care practice, the fit between skills and attributes, and a significant experience in a primary care setting. Factors that seemed to influence retention were subspecialisation and portfolio careers, and job satisfaction. The most important determinants of recruitment and retention were intrinsic and idiosyncratic factors, such as recognition, rather than extrinsic factors, such as income.

\section{Conclusion}

Although the published evidence relating to GP recruitment and retention is limited, and most focused on attracting GPs to rural areas, the authors found that there are clear overlaps between strategies to increase recruitment and retention. Indeed, the most influential factors are idiosyncratic and intrinsic to the individuals.

\section{Keywords}

general practice; intrinsic motivation; job satisfaction; primary health care; recruitment; retention; review, systematic.

\section{INTRODUCTION}

The UK government and professional bodies have become increasingly concerned about the declining numbers of GPs. The reasons for this are thought to be related to problems in training, low GP morale, increasing workload pressures on practices, challenges of changing roles, and reductions in pay. ${ }^{1-4}$

The number of GPs per 100000 head of population across England declined from 62 in 2009 to 59.5 in $2012 .{ }^{5}$ Despite Department of Health policy to increase GP training numbers in England to 3250 per annum, GP recruitment has remained persistently below this target, at around 2700 per annum, and since 2005 there has been a gradual decline in the percentage of students choosing general practice as a first choice. ${ }^{6}$ Despite a recruitment record of 2989 in 2015-2016, Health Education England () missed their recruitment goal of 3250 new GP trainees.? Although applications for general practice postqualifying have substantially increased in 2016, the problem remains in some areas, such as in the North East, North West, and Midlands. ${ }^{7.8}$ This reduction is set against an increasing GP workload due to changing health needs and policies designed to develop more primary and communitybased health care. ${ }^{9-12}$

Additional pressure arises from an increase in the numbers of GPs leaving general practice, including an increase in those considering practising abroad. ${ }^{13,14}$ Together, under-recruitment of GPs and increased propensity to leave are key factors

C Marchand, PhD, research assistant; S Peckham BSc, MA, HMFPH, professor, Centre for Health Services Studies, University of Kent, Canterbury, Kent.

\section{Address for correspondence}

Catherine Marchand, Centre for Health Services Studies, University of Kent, Canterbury, Kent,

CT2 7NZ, UK.

E-mail: C.Marchanddakent.ac.uk in the current GP shortage. To address this, NHS England - working with HEE, the Royal College of General Practitioners (RCGP) and the British Medical Association (BMA) - in 2015 published Building the Workforce - the New Deal for General Practice, ${ }^{15}$ where they presented the 10-point plan, then in 2016 the General Practice Forward $V i e w_{1}^{16}$ both proposing strategies to increase recruitment and reduce turnover in general practice through specific initiatives and further investment in general practice.

As part of the development work for reviewing the 10-point plan and NHS England's strategy, the Policy Research Unit in Commissioning and the Healthcare System (PRUComm) was asked to review the existing evidence on GP recruitment and retention. ${ }^{17}$ The review explored the main dimensions related to recruitment and retention of GPs to identify the intrinsic and extrinsic motivational factors connected to career choices and retention. This study reports on the main findings of the review.

\section{METHOD}

To identify relevant evidence, the authors undertook a structured review that synthesised the evidence from reviews on primary care physician recruitment and retention from countries with similar health systems to the UK (for example, Canada and Australia), and UK studies specifically examining GP recruitment and retention and GP training (search terms are outlined in Appendix 1). Articles published in English from 1990 onwards were included.

Submitted: 17 August 2016; Editor's response: 18 October 2016; final acceptance: 19 December 2016

\section{OBritish Journal of General Practice}

This is the full-length article (published online 14 Mar 2017) of an abridged version published in print. Cite this version as: Br J Gen Pract 2017; DOI: https://doi.org/10.3399/bjgp17X689929 


\section{How this fits in}

To support the work of NHS England and Health Education England on the development of the Five Year Forward View. the Department of Health commissioned a review of the evidence of the 10-point plan from Building the Workforce - the New Deal for General Practice from the Policy Research Unit in Commissioning and the Healthcare System. The review examined the evidence on GP recruitment and retention determinants, and found that intrinsic and idiosyncratic factors, such as job satisfaction, were more important than extrinsic factors, such as financial incentives.

Following an initial review, the terms were searched as keywords lappearing in title, abstract, subject, and keyword heading fields) and also mapped against $\mathrm{MeSH}$ subject headings, where applicable, to ensure comprehensive coverage. The databases searched were Medline, Embase, Cochrane Library, Health Management Information Consortium (HMIC), Cumulative Index to Nursing and Allied Health Literature (Cinahl), PsyclNFO, and the Turning Research Into Practice (TRIP) database (an internet-based source of evidence-based research). The literature search included all journal articles, systematic reviews, meta-analyses, review articles, reports, and grey literature (Table 1 contains the search results). The authors also expanded their data collection to undertake more in-depth searching of the grey literature and conducted hand searches of key journals to provide a more comprehensive analysis and evidence base for policy development. The search was restricted to English-language studies in journals from countries that are part of the Organisation for Economic Cooperation and Development (OECD) and selected articles generally came from

\section{Table 1. Search results}

\section{Database}

Studies, $n$

\begin{tabular}{lc}
\hline Medline, Embase, and Cochrane (reviews, meta-analyses) & 129 \\
\hline HMIC (reports, policy documents, and grey literature) & 270 \\
\hline Medline, Embase, and Cochrane (journal articles) & 879 \\
\hline PsycINFO & 351 \\
\hline Cinahl & 43 \\
\hline TRIP & 30
\end{tabular}

Cinahl = Cumulative Index to Nursing and Allied Health Literature. HMIC = Health Management Information Consortium. TRIP = Turning Research Into Practice. countries with similar healthcare systems, such as Canada and Australia.

Duplicates were deleted and a basic initial weeding process was undertaken to exclude irrelevant papers. The research team reviewed the titles and abstracts of identified articles to select relevant studies for inclusion in the review. Original research papers and empirical studies (Figure 18) were reviewed, both from the UK and from other countries where relevant.

\section{RESULTS}

There was a degree of overlap between studies that examined retention and which also studied recruitment. However, in order to set the evidence on recruitment and retention determinants, these are presented separately.

\section{Recruitment in general practice}

Studies that examine specific recruitment strategies for the GP workforce are scarce. ${ }^{19}$ This review suggests that most studies on primary care physician recruitment (for example, GPs and family doctors) have predominantly focused on remote rural locations. However, the authors identified a number of studies that examined the determinants influencing recruitment that would be relevant to general practice. These can be characterised in terms of how they relate to the individual, institutional, and professional contexts of recruitment.

In a study of career choices, Shadbolt and Bunker ${ }^{20}$ presented determinants that are mainly intrinsic to the individual. These intrinsic factors include physicians' self-awareness of their skills, and the factors associated with career orientations or choices. These are influenced by demographic variables, lifestyle orientation, and the opportunities for learning and educational development, ${ }^{20-23}$ suggesting that medical graduates primarily look for a career that is stimulating and interesting. One study found that medical students were more attracted towards biomedical or technical forms of medical practice, as opposed to a more holistic form of medicine. ${ }^{21}$

Medical students exposure to, and experience of, general practice has an important effect on preferences for a career in general practice. The authors identified a number of studies that highlighted the important influence on recruitment of the workplace experience, stressing the need for a positive experience from interactions with members of the profession, the length of time spent in general practice, the quality of the practice, and the dedication of the 


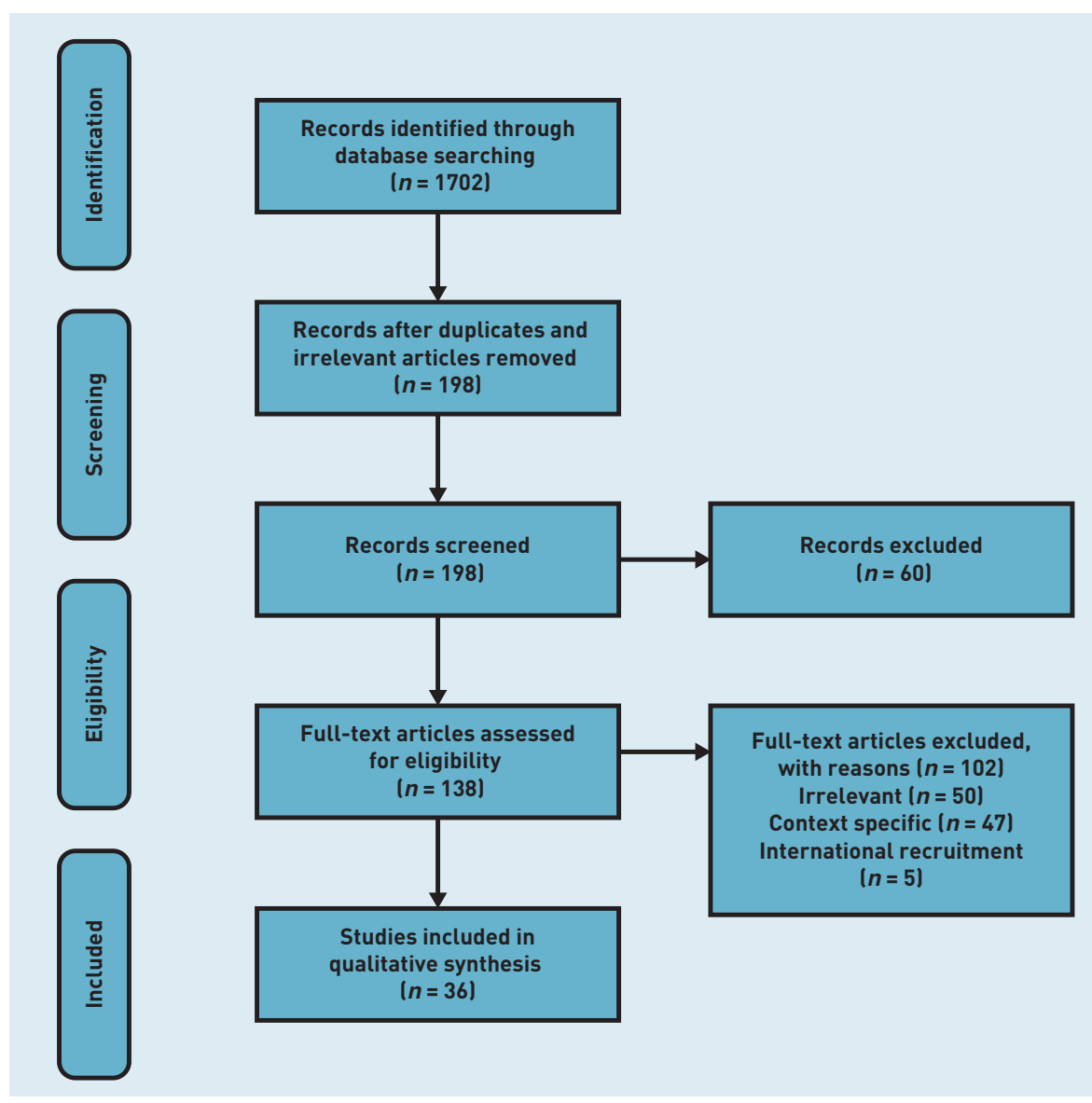

Figure 1. Flow chart of identification and inclusion of studies for review. Adapted with permission from the PRISMA statement. ${ }^{18}$ generalists' faculty. ${ }^{19-21,24-29}$ In particular, positive experiences were linked to an increased likelihood to choose general practice; especially when the experience occurred at the pre-clinical or early stage. 25,29

Similarly, Campos-Outcalt et $a^{30}$ found that the best strategies to enlarge the proportion of medical students choosing generalist careers included reform of the medical school curricula with emphasis on generalist training, increasing the size of generalist faculties, and ensuring there is clinical training in family practice training. There is some evidence to show that implementing effective medical school curricula in primary care and establishing primary care honours tracks, developing or expanding primary care fast-track programmes, and developing curricula proposing portfolio careers and profile of new skills 20,28,30,31 influences students' career choices. Currently, medical training delivered in general practice, and the proportion of the medical school budget made available for its teaching, is lower than the time dedicated to, and resources available for, teaching related to secondary care. ${ }^{2}$

Two studies focused on the effect of the modification of admission criteria to identify potential students who are more likely to choose primary care specialisation as part of student selection. They proposed that assessing the community of origin and previous experience of, or interest in, people and social concerns, and discussing future specialty choices be integrated into the admission process. ${ }^{32,33}$ Providing financial support to students choosing poorly recruiting areas of practice has been shown to have a negative impact on retaining those students when in practice. ${ }^{34}$ However, increases in student debt from higher tuition fees may make such schemes more attractive, although further research is required. ${ }^{20,27}$

Factorsinfluencing recruitmentare related to the clinical content, perceived lifestyle, and work context. The clinical content of the role is one of the most important factors influencing career choices. ${ }^{23}$ Given this dominance, the negative view of general practice held by medical students - that it is less intellectually stimulating - may explain the lack of interest in this career choice. 20,23 However, Chellappah and Garnham $^{21}$ concluded that students at the end of their training have a positive image of general practice, suggesting that students' views change during medical training, but choices regarding eventual specialty are taken earlier in medical school, before these more positive views are formed.

Work climate and work context, such as the support from colleagues, autonomy, flexibility and independence, proximity with patients, the continuity of care, and health promotion, are also key factors affecting recruitment. 20,21,23,35,36 Compatibility with family life and the medical breadth of the discipline also positively influence choosing general practice. ${ }^{36}$

Shadbolt and Bunker ${ }^{20}$ have suggested that more attention should be paid to the fit between skills and attributes with intellectual content and demands of primary medical care, by emphasising the lifestyle issues (flexibility or work-life balance), social orientation (patient focused or community based), and the opportunity to gain significant and varied clinical experience in the primary care setting.

\section{Retention of GPs}

Few studies explicitly examined how to retain primary care physicians in practice. In the UK, the numbers of GPs registering to work abroad has significantly increased in the past 3 years, and GPs' intention to quit practice has been increasing: from $8.9 \%$ in 2012 to $13.1 \%$ in 2015 among GPs $<50$ years old, and from $54.1 \%$ in 2012 to $60.9 \%$ in 2015 


\section{Table 2. Summary of evidence to support GP recruitment and retention, using a framework adapted from the}

10-point plan from Building the Workforce - the New Deal for General Practice document. ${ }^{15}$

\begin{tabular}{|c|c|c|c|}
\hline & 10-point plan & Evidence from GP literature & \\
\hline \multirow{5}{*}{ 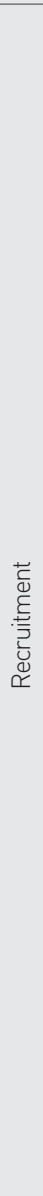 } & 1. Promoting general practice & No clear evidence & $\begin{array}{l}\text { - Enhancing the status, contribution, career advancement, and } \\
\text { rewards of primary care practitioners } \\
\text { - Role models } \\
\text { - Medical environment important }\end{array}$ \\
\hline & $\begin{array}{l}\text { 2. Improving the breadth of training } \\
\text { (for candidates seeking to work in } \\
\text { geographies where it is hard to } \\
\text { recruit trainees) }\end{array}$ & $\begin{array}{l}\text { Some evidence both for candidates } \\
\text { seeking to work in geographies } \\
\text { where it is hard to recruit trainees, } \\
\text { and for GP trainees seeking to } \\
\text { work everywhere }\end{array}$ & $\begin{array}{l}\text { Exposure to general practice: } \\
\text { - Early exposure/pre-registration house officer scheme } \\
\text { - Workplace experience and interaction with members of the profession } \\
\text { - Length of time spent in general practice rotation } \\
\text { - Ensuring that the rotations are of high quality, with dedicated } \\
\text { generalists faculty } \\
\text { Curricula modifications: } \\
\text { - Effective medical school curricula in primary care } \\
\text { - Establish primary care honours or scholars tracks } \\
\text { - Develop or expand primary care fast-track programmes } \\
\text { - Subspecialisation, portfolio careers, and profile of new skills } \\
\text { Recruitment/admission: } \\
\text { - Modification of selection criteria }\end{array}$ \\
\hline & 3. Training hubs & $\begin{array}{l}\text { Some evidence in the rural training } \\
\text { and context literature }\end{array}$ & $\begin{array}{l}\text { Rural training, rural context literature: } \\
\text { - Familiarity with community health resources, sociocultural awareness } \\
\text { in patient care, community participation and assimilation, and identifying } \\
\text { and intervening in the community's health problems }\end{array}$ \\
\hline & 4. Targeted support & $\begin{array}{l}\text { Some evidence in the rural training } \\
\text { and context literature, but no clear } \\
\text { evidence in general practice }\end{array}$ & $\begin{array}{l}\text { - Link choice of career in primary care to loan forgiveness } \\
\text { - Funding in primary care research } \\
\text { - Increase and assure funding for fellowship training in primary care } \\
\text { - Direct training funds to schools with track records of } \\
\text { producing graduates in primary care }\end{array}$ \\
\hline & Other & & $\begin{array}{l}\text { Determinant factors in specialisation choice: } \\
\text { - Fit between skills and attributes with intellectual content and demands of } \\
\text { the specialisation } \\
\text { - Stimulating and interesting } \\
\text { - Lifestyle factors (flexibility, work-life balance, or quality of life) } \\
\text { - Social orientation and desire for a varied scope of practice } \\
\text { - Significant experience in the primary care setting }\end{array}$ \\
\hline \multirow{5}{*}{ 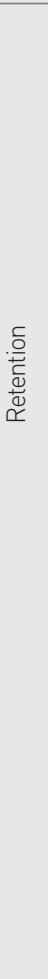 } & 5. Investment in retainer schemes & No clear evidence & $\begin{array}{l}\text { Widening the scope of remuneration and contract conditions: } \\
\text { - Reduce the income differential between general practice and hospital work } \\
\text { - Remove the disincentives for less than full-time employment, widening of } \\
\text { the employment mechanisms open to GPs, such as authority-organised } \\
\text { salaried schemes }\end{array}$ \\
\hline & $\begin{array}{l}\text { 6. Improving the training capacity } \\
\text { in general practice }\end{array}$ & No clear evidence & $\begin{array}{l}\text { Subspecialisation and portfolio careers where doctors might gain skills in a } \\
\text { range of specialties and practices, some or all of them at any one time }\end{array}$ \\
\hline & 7. Incentives to remain in practice & No clear evidence & \\
\hline & 8. New ways of working & No clear evidence & $\begin{array}{l}\text { Varying time commitment across the working day and week: } \\
\text { - Part time, job share, temporary, and short time available, } \\
\text { GP's employment status and career stage } \\
\text { Offering a wider choice of long-term career paths: } \\
\text { - Locum and associate positions equal to full-time principal posts } \\
\text { - Activities such as research and training in management skills } \\
\text { - A part-time educational post or hospital attachment } \\
\text { - Job mobility as a way to progress (a more positive vision of mobilityl }\end{array}$ \\
\hline & Other & Evidence & $\begin{array}{l}\text { Increased satisfaction (factors): } \\
\text { - Job autonomy/diversity/variety } \\
\text { - Social support, relationship and collaboration with colleagues/patients } \\
\text { - Academic hospital and centres/teaching medical students and advanced } \\
\text { students } \\
\text { Decreased satisfaction (factors): } \\
\text { - Too many working hours, low income/compensation/workload/not } \\
\text { enough time/ high demands/lot of paperwork/little free time } \\
\text { - Lack of support/lack of colleagues } \\
\text { - Lack of recognition } \\
\text { - Bureaucracy/practice administration }\end{array}$ \\
\hline
\end{tabular}


among GPs aged $\geq 50$ years. ${ }^{14}$ Retention can be influenced by a variety of intrinsic and extrinsic factors, including remuneration, income and salary retention schemes, job satisfaction, and career pathway and portfolio. ${ }^{15,16,37}$

Although remuneration and retention schemes, such as increases in salary or lump sum payments, are used by the government to retain doctors, there is little evidence of the positive and effective impact of these schemes. Low pay might be a source of dissatisfaction with the job, ${ }^{27}$ but the evidence suggests that increases in income would not compensate for other sources of job dissatisfaction, such as workload. ${ }^{37}$

Job satisfaction and job dissatisfaction are significant predictors of GP retention and turnover, 38,39 reflecting the findings of research in the wider management and organisational behaviour literature. ${ }^{40,41} \mathrm{Job}$ satisfaction varies from time to time within an individual's career stages. Therefore, it is important to understand both the determinants influencing job satisfaction and dissatisfaction, and also the factors that increase strain in the workplace and in general practice. Job satisfaction and dissatisfaction are related to three factors: job stressors (for example, workload), job characteristics and attributes (for example, job autonomy), and other conditions (for example, practice geographical location).

Job dissatisfaction is most influenced by work-related variables. In particular, these include increased workload intensity and volume to meet the requirements of external agencies, having insufficient time to do the job justice, increased administration and bureaucracy, increased demand and expectation from patients, increasing work complexity, lack of support from colleagues, lack of professional recognition, and long working hours. 14,39,40,42 More recently, adverse publicity from the media, changes imposed from local primary care organisations, and insufficient resources within the practice have all increased job dissatisfaction. ${ }^{13}$ There is evidence to show that increased work stress and work intensity leads GPs under 'high strain' to report higher levels of anxiety, depression, and dissatisfaction than GPs under 'low strain', and that the health impacts of stress continued outside of work, which in turn could increase job dissatisfaction and intention to quit the profession..$^{43,44}$

Job satisfaction is also influenced by expectations about future events. ${ }^{45}$ If doctors perceive that their workload will not reduce, and that demands will always increase, it is likely that they will feel more overwhelmed and less satisfied with their job, and thus more likely to quit. Therefore, feeling more stressed, disillusioned, and overwhelmed amplifies the negative portrayal of GPs in the media and by government, further negatively affecting GPs' spirit and professional identity. ${ }^{46}$

There is some evidence that job autonomy, the variety of work, the feeling of doing an important job, social support, and a good practice environment positively affect job satisfaction. 14,39,47 However, GP surveys suggest that a number of these attributes have changed between 2012 and 2015; such as the autonomy in deciding how to do their job and what work to do, the variety of work, and flexibility of working. ${ }^{14}$

Changes to general practice over the last 10-15 years have been substantial, and job dissatisfaction could be a result of the changing roles necessitated by professional and organisational changes. ${ }^{38,47}$ However, job satisfaction is also influenced by a number of other factors, such as the local practice context, work-life flexibility, personal development, and the emotional impact of working as a GP.42,47 Wordsworth et al ${ }^{48}$ suggested that enhancing the patient care aspects of a GP's work is more likely to act as a key for retention, and that lack of consultation on changes can lead to dissatisfaction. ${ }^{49}$ Flexibility and part-time working have always been seen as factors that make general practice a more attractive working environment, although this is increasingly seen to be less relevant. ${ }^{48,50-52}$

Mentorship schemes and opportunities to develop portfolio careers would be welcome at every stage of a GP's career, not just for senior doctors or towards the end of working lives. ${ }^{20,26,29}$ Two papers suggest that a wider choice of long-term career paths, such as subspecialisation and portfolio careers (for example, dermatology or paediatrics), is important for both the recruitment and retention of GPs. It is also suggested that an increase in satisfaction of intellectual and altruistic needs, and functional flexibility within their practice, could improve satisfaction and fulfilment, and consequently GPs' retention. ${ }^{20,29}$ Providing learning and development activities, such as developing management skills, could support GP recruitment and retention, providing an opportunity for students to map out development pathways and provide variety within a physician's role.

\section{DISCUSSION}

\section{Summary}

Three elements are relevant to GP 
recruitment: individual, institutional, and professional factors. In addition, providing students with appropriate opportunities for contact with, and positive exposure to, general practice and GPs is critical, as well as widening the opportunities for students and GPs so that junior doctors' specialisation choices can reflect more individual student characteristics. The main determinants of retention are job satisfaction lversus dissatisfaction), the influence of job stress, job attributes and characteristics, and other conditions, such as the geographical location of the practice. All seem related to career pathways and portfolio.

Based on this review of the evidence, the authors would support strategies that provide long-term investment in general practice. Current proposals to increase the proportion of NHS funding in primary care are therefore welcome. The evidence suggests that providing the right environment and opportunity for GPs to focus on supporting patients as medical professionals is crucial, requiring strategies that reduce workload while retaining the core attributes of general practice. However, strategies should also include opportunities for GPs to develop wider interests and skills, and should take into consideration both recruitment and retention simultaneously. From this review, there appear to be three key lessons that should underpin national and local policies:

- review the curricula in medical schools and emphasise the importance of exposure to general practice;

- job satisfaction is the main predictor of retention and is influenced by workload stress and future anticipation, and thus strategies that reduce workload are required; and

- financial inducements (golden handcuffs) are not necessarily effective.

\section{Strengths and limitations}

Overall, the published evidence in relation to GP recruitment and retention is limited and mostly focuses on attracting GPs to rural areas - particularly in Australia. The review shows an overlap in the determinants of recruitment and retention. ${ }^{47}$ Despite this, the evidence suggests that there are some potential factors that may usefully support the development of specific strategies for supporting the recruitment and retention of GPs. These are summarised in Table 2 and Appendix 2. Although most strategies proposed by the 10-point plan from the document Building the Workforce - the New Deal for General Practice and the General Practice Forward View are not based on strong evidence, some determinants might help with the GP workforce crisis. ${ }^{15,16}$

\section{Implications for research and practice}

Newton et al found that retirement at 60 years old was a goal for both happy GPs - in order to do other things or because they feel they have 'done their bit' - and those GPs who no longer had the resilience to cope with work stress. ${ }^{50}$ In their study, Roos et al showed that, although 83.7\% of GP trainees and newly qualified GPs would choose to be a physician again, only $78.4 \%$ would choose general practice as a specialisation. ${ }^{36}$ One clear message from the literature is that expectations about the future - whether as a new GP or because of future developments in general practice - affect both recruitment and retention. ${ }^{45,53}$

One area not fully explored in the literature identified for this review was the recruitment policy of medical schools, given that that there are career choice determinants influencing the recruitment of GPs in medical school. It would be interesting in the future to explore the role of health policy on the specific recruitment policy of medical schools, and this is likely to be influenced by the findings of the joint HEE and Medical Schools Council review chaired by Professor Val Wass. ${ }^{54,55}$ The General Practice Forward View has suggested recruitment at the international level. International recruitment was outside the scope of this review. A post-hoc analysis shows a lack of evidence of the long-term beneficial effects of such recruitment strategy. ${ }^{56-60}$ Short-term policies, such as international recruitment, financial bonuses, and other incentive packages, may respond to immediate needs, but are not long-term solutions.

The authors have declared no competing interests.

\section{Acknowledgements}

The authors thank Ms Anna Peckham, consultant librarian, for her assistance in the literature search.

\section{Discuss this article}

Contribute and read comments about this article: bjgp.org/letters 


\section{REFERENCES}

1. Gillam S, Siriwardena AN. Evidence-based healthcare and quality improvement. Qual Prim Care 2014; 22(3): 125-132.

2. Harding A, Rosenthal J, Al-Seaidy M, et al. Provision of medical student teaching in UK general practices: a cross-sectional questionnaire study. Br J Gen Pract 2015; DOI: https://doi.org/10.3399/bjgp15X685321\&\#39.

3. Hobbs FD, Bankhead C, Mukhtar T, et al. Clinical workload in UK primary care: a retrospective analysis of 100 million consultations in England, 2007-14. Lancet 2016; 387(10035): 2323-2330.

4. Jones D. GP recruitment and retention. Br J Gen Pract 2015; DOI: https://doi. org/10.3399/bjgp15X684721\&\#39.

5. NHS. The Information Centre for health and social care. NHS workforce: summary of staff in the NHS: results from September 2012 census. 2013. http:// content.digital.nhs.uk/catalogue/PUB10392/nhs-staf-2002-2012-over-rep.pdf (accessed 24 Feb 2017)

6. Svirko E, Goldacre MJ, Lambert T. Career choices of the United Kingdom medical graduates of 2005, 2008 and 2009: questionnaire surveys. Med Teach 2013; 35(5): 365-375

7. Thomas R. HEE misses GP training target despite record recruitment. Health Serv J 2016; 20 Oct: https://uww.hsj.co.uk/sectors/primary-care/hee-missesgp-training-target-despite-record-recruitment/7011651.article laccessed 24 Feb 2017).

8. Millet D. Health education chiefs identify 5,000 GP recruitment target as 'greatest risk'. GP2016; 21 Jul: http://www.gponline.com/health-education-chiefsidentify-5000-gp-recruitment-target-greatest-risk/article/1403071 laccessed 13 Feb 2017).

9. Department of Health. Primary care delivering the future. London: DH, 1996.

10. Department of Health. The new NHS: modern, dependable. London: DH, 1997.

11. Department of Health. The NHS plan: a plan for investment, a plan for reform. London: DH, 2000

12. Department of Health. Our health, our care, our say: a new direction for community services. London: $\mathrm{DH}, 2006$.

13. Davis J. 800 GPs applying for permit to work abroad every year. Pulse 2015; 6 Aug: http://uww.pulsetoday.co.uk/your-practice/regulation/800-gps-applyingfor-permit-to-work-abroad-every-year/20010699.article laccessed 13 Feb 2017).

14. Gibson J, Checkland K, Coleman A, et al. Eighth national GP worklife survey. Manchester: Policy Research Unit in Commissioning and the Healthcare System, 2015. http://www.population-health.manchester.ac.uk/ healtheconomics/research/Reports/EighthNationalGPWorklifeSurveyreport/ EighthNationalGPWorklifeSurveyreport.pdf (accessed 15 Feb 2017).

15. Royal College of General Practitioners, British Medical Association, NHS England, Health Education England. Building the workforce - the new deal for general practice. 2015. https://www.england.nhs.uk/commissioning/wp-content/ uploads/sites/12/2015/01/building-the-workforce-new-deal-gp.pdf laccessed 13 Feb 2017).

16. NHS England. General practice forward view. 2016. https://www.england.nhs.uk/ gp/gpfv/ laccessed 15 Feb 2017).

17. Peckham S, Marchand C, Peckham A. General practitioner recruitment and retention: an evidence synthesis. Final report. Canterbury: Policy Research Unit in Commisioning and the Healthcare System, 2016. https://kar.kent. ac.uk/58788/1/PRUComm\%20General\%20practitioner\%20recruitment\%20 and\%20retention\%20review\%20Final\%20Report.pdf laccessed 13 Feb 2017).

18. Moher D, Liberati A, Tetzlaff J, Altman DG, for the PRISMA Group. Preferred reporting items for systematic reviews and meta-analyses: the PRISMA statement. BMJ 2009; 339: b2535.

19. Verma P, Ford JA, Stuart A, et al. A systematic review of strategies to recruit and retain primary care doctors. BMC Health Serv Res 2016; 16: 126.

20. Shadbolt N, Bunker J. Choosing general practice: a review of career choice determinants. Aust Fam Physician 2009; 38(1-2): 53-55.

21. Chellappah M, Garnham L. Medical students' attitudes towards general practice and factors affecting career choice: a questionnaire study. London J Prim Care 2014; 6(6): 117-123.

22. Crampton PES, McLachlan JC, Illing JC. A systematic literature review of undergraduate clinical placements in underserved areas. Med Educ 2013; 47(10): 969-978

23. Petchey R, Williams J, Baker M. 'Ending up a GP': a qualitative study of junior doctors' perceptions of general practice as a career. Fam Pract 1997; 14(3): $194-198$.
24. Halaas GW, Zink T, Finstad D, et al. Recruitment and retention of rural physicians: outcomes from the rural physician associate program of Minnesota. $J$ Rural Health 2008; 24(4): 345-352.

25. Illing J, Van Zwanenberg T, Cunningham WF, et al. Preregistration house officers in general practice: review of evidence. BMJ 2003; 326(7397): 1019-1022.

26. Landry M, Schofield A, Bordage R, Belanger M. Improving the recruitment and retention of doctors by training medical students locally. Med Educ 2011; 45: $1121-1129$.

27. Lee DM, Nichols T. Physician recruitment and retention in rural and underserved areas. Int J Health Care Qual Assur 2014; 27(7): 642-652.

28. Schwartz MD, Basco WT Jr, Grey MR, et al. Rekindling student interest in generalist careers. Ann Intern Med 2005; 142(8): 715-724.

29. Young $\mathrm{R}$, Leese $\mathrm{B}$. Recruitment and retention of general practitioners in the UK: what are the problems and solutions? Br J Gen Pract 1999; 49(447): 829-833.

30. Campos-Outcalt D, Senf J, Watkins AJ, Bastacky S. The effects of medical school curricula, faculty role models, and biomedical research support on choice of generalist physician careers: a review and quality assessment of the literature. Acad Med 1995; 70(7): 611-619.

31. Williamson JW, Walters K, Cordes DL. Primary care, quality improvement, and health systems change. Am J Med Qual 1993; 8(2): 37-44.

32. Rosenthal TC. Outcomes of rural training tracks: a review. J Rural Health 2000; 16(3): 213-216.

33. Geyman JP, Hart LG, Norris TE, et al. Educating generalist physicians for rural practice: how are we doing? J Rural Health 2000; 16(1): 56-80.

34. Bustinza R, Gagnon S, Burigusa G. [The decentralized training programme and the retention of general practitioners in Quebec's Lower St Lawrence Region]. [Article in French]. Can Fam Physician 2009; 55(9): e29-e34.

35. Hemphill E, Kulik CT. Segmenting a general practitioner market to improve recruitment outcomes. Aust Health Rev 2011; 35(2): 117-123.

36. Roos M, Watson J, Wensing M, Peters-Klimm F. Motivation for career choice and job satisfaction of GP trainees and newly qualified GPs across Europe: a seven countries cross-sectional survey. Educ Prim Care 2014; 25(4): 202-210.

37. Dayan M, Arora S, Rosen R, Curry N. Is general practice in crisis? London: Nuffield Trust, 2014.

38. Sibbald B, Enzer I, Cooper C, et al. GP job satisfaction in 1987, 1990 and 1998: lessons for the future? Fam Pract 2000; 17(5): 364-371.

39. Sibbald B, Bojke C, Gravelle H. National survey of job satisfaction and retirement intentions among general practitioners in England. BMJ 2003; 326(7379): 22.

40. Van Ham I, Verhoeven AAH, Groenier KH, et al. Job satisfaction among general practitioners: a systematic literature review. Eur J Gen Pract 2006; 12(4): 174180.

41. Griffeth RW, Hom PW, Gaertner S. A meta-analysis of antecedents and correlates of employee turnover: update, moderator tests, and research implications for the next millennium. J Manag 2000; 26(3): 463-488.

42. Buciuniene I, Blazeviciene A, Bliudziute E. Health care reform and job satisfaction of primary health care physicians in Lithuania. BMC Fam Pract 2005 6(1): 10.

43. Dale J, Potter R, Owen $\mathrm{K}$, et al. Retaining the general practitioner workforce in England: what matters to GPs? A cross-sectional study. BMC Fam Pract 2015; 16: 140 .

44. Groenewegen PP, Hutten JB. Workload and job satisfaction among general practitioners: a review of the literature. Soc Sci Med 1991; 32(10): 1111-1119.

45. O'Connor DB, O'Connor R, White B, Bundred P. Job strain and ambulatory blood pressure in British general practitioners: a preliminary study. Psychol Health Med 2000; 5(3): 241-250.

46. Buchbinder SB, Wilson M, Melick CF, Powe NR. Primary care physician job satisfaction and turnover. Am J Manag Care 2001; 7(7): 701-713.

47. Doran N, Fox F, Rodham K, et al. Lost to the NHS: a mixed methods study of why GPs leave practice early in England. Br J Gen Pract 2016; DOI: https://doi. org/10.3399/bjgp16X683425\&\#39.

48. Wordsworth S, Skåtun D, Scott A, French F. Preferences for general practice jobs: a survey of principals and sessional GPs. Br J Gen Pract 2004; 54(507): 740-746.

49. Humphreys J, Jones J, Jones $M$, et al. A critical review of rural medical workforce retention in Australia. Aust Health Rev 2001; 24(4): 91-102.

50. Newton J, Luce A, Van Zwanenberg T, Firth-Cozens J. Job dissatisfaction and early retirement: a qualitative study of general practitioners in the Northern Deanery. Prim Health Care Res Dev 2004; 5(1): 68-76. 
51. Centre for Workforce Intelligence. In-depth review of the general practitioner workforce. London: CfWl, 2014.

52. Evans J, Goldacre MJ, Lambert TW. Views of UK medical graduates about flexible and part-time working in medicine: a qualitative study. Med Educ 2000; 34(5): 355-362.

53. Feeley $\mathrm{TH}$. Using the theory of reasoned action to model retention in rural primary care physicians. J Rural Health 2003; 19(3): 245-251.

54. Matthews-King A. Education bosses launch landmark review into GP attitude in medical schools. Pulse 2016; 2 Mar: http://www.pulsetoday.co.uk/your-practice/ practice-topics/education/education-bosses-launch-landmark-review-into-gpattitude-in-medical-schools/20031274.fullarticle laccessed 13 Feb 2017).

55. Wass V, Gregory S, Petty-Saphon K. By choice - not by chance: supporting medical students towards future careers in general practice. London: Medical Schools Council and Health Education England, 2016.

56. Bradby H. International medical migration: a critical conceptual review of the global movements of doctors and nurses. Health (London) 2014; 18(6): 580-596.
57. Buchan J, Dovlo D. Department for International Development Health Systems Resource Centre. International recruitment of health workers to the UK: a report for DFID: final report. London: DFID HSRC, 2004.

58. Legido-Quigley H, Saliba V, McKee M. Exploring the experiences of EU qualified doctors working in the United Kingdom: a qualitative study. Health Policy 2015; 119(4): 494-502.

59. Lozano M, Meardi G, Martín-Artiles A. International recruitment of health workers. British Lessons for Europe? Emerging concerns and future research recommendations. Int J Health Serv2015; 45(2): 306-319.

60. Young $\mathrm{R}$, Noble J, Mahon $\mathrm{A}$ et al Evaluation of international recruitment of health professionals in England. J Health Serv Res Policy 2010; 15(4): 195-203.

61. Hemphill E, Dunn S, Barich H, Infante R. Recruitment and retention of rural general practitioners: a marketing approach reveals new possibilities. Aust $J$ Rural Health 2007; 15(6): 360-367.

62. Stapleton G, Schroder-Back P, Brand H, Townend D. Health inequalities and regional specific scarcity in primary care physicians: ethical issues and criteria. Int J Public Health 2014: 59(3): 449-455.

\section{Appendix 1. Search terms}

Key terms

General practitioner

GPs

General practice

Family practitionera

Family practice

Family physician ${ }^{\text {a }}$

Family doctor

Primary care physician ${ }^{a}$

Primary care doctor ${ }^{a}$

Primary care practitioner ${ }^{\mathrm{a}}$
Combined with:

Recruitment

Recruitment strategy

Personnel recruitment

Employment

Career choice

Personnel turnover

Motivation

Retention

GP retention

Retirement

Early retirement

Truncation. 


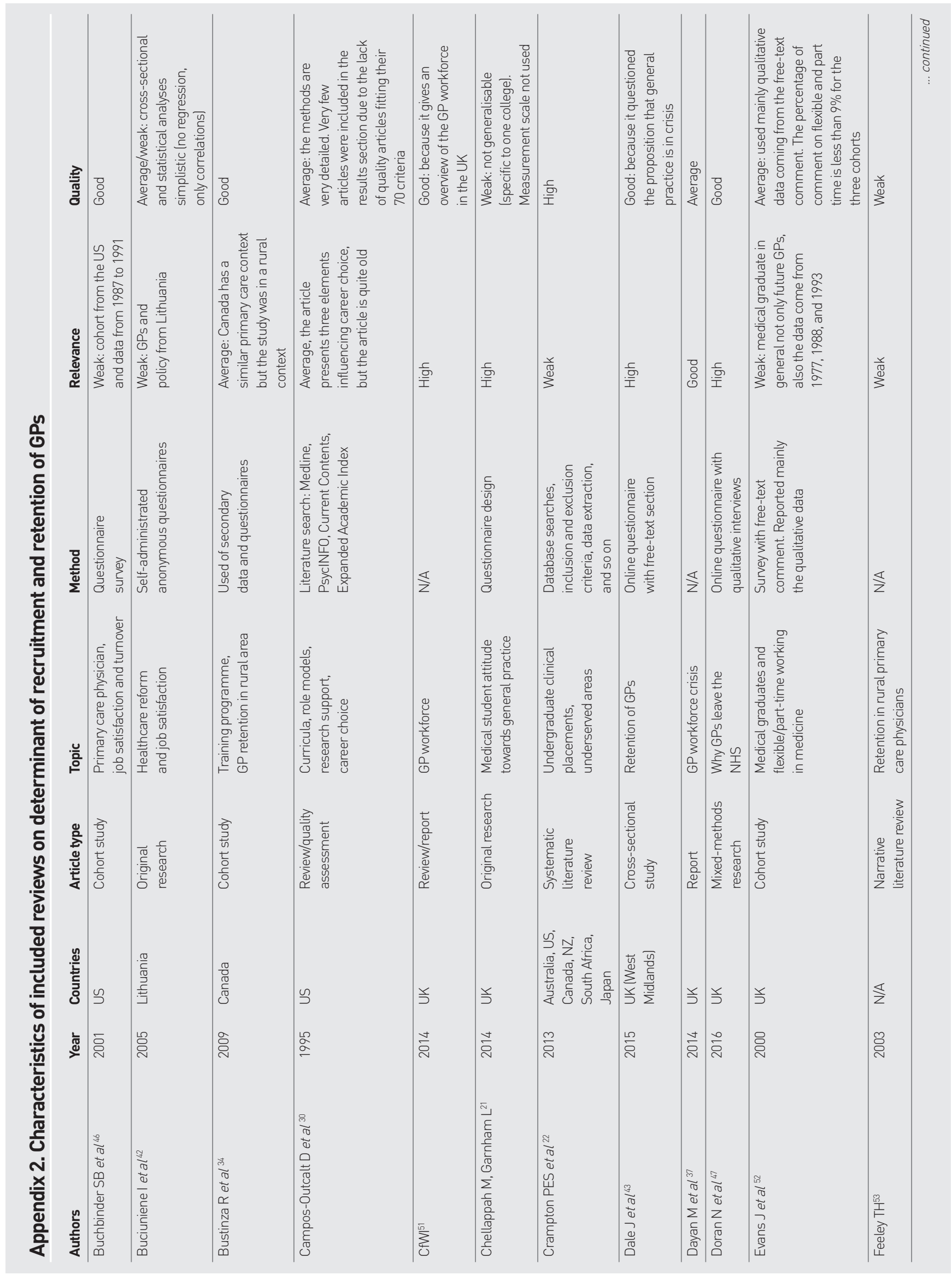




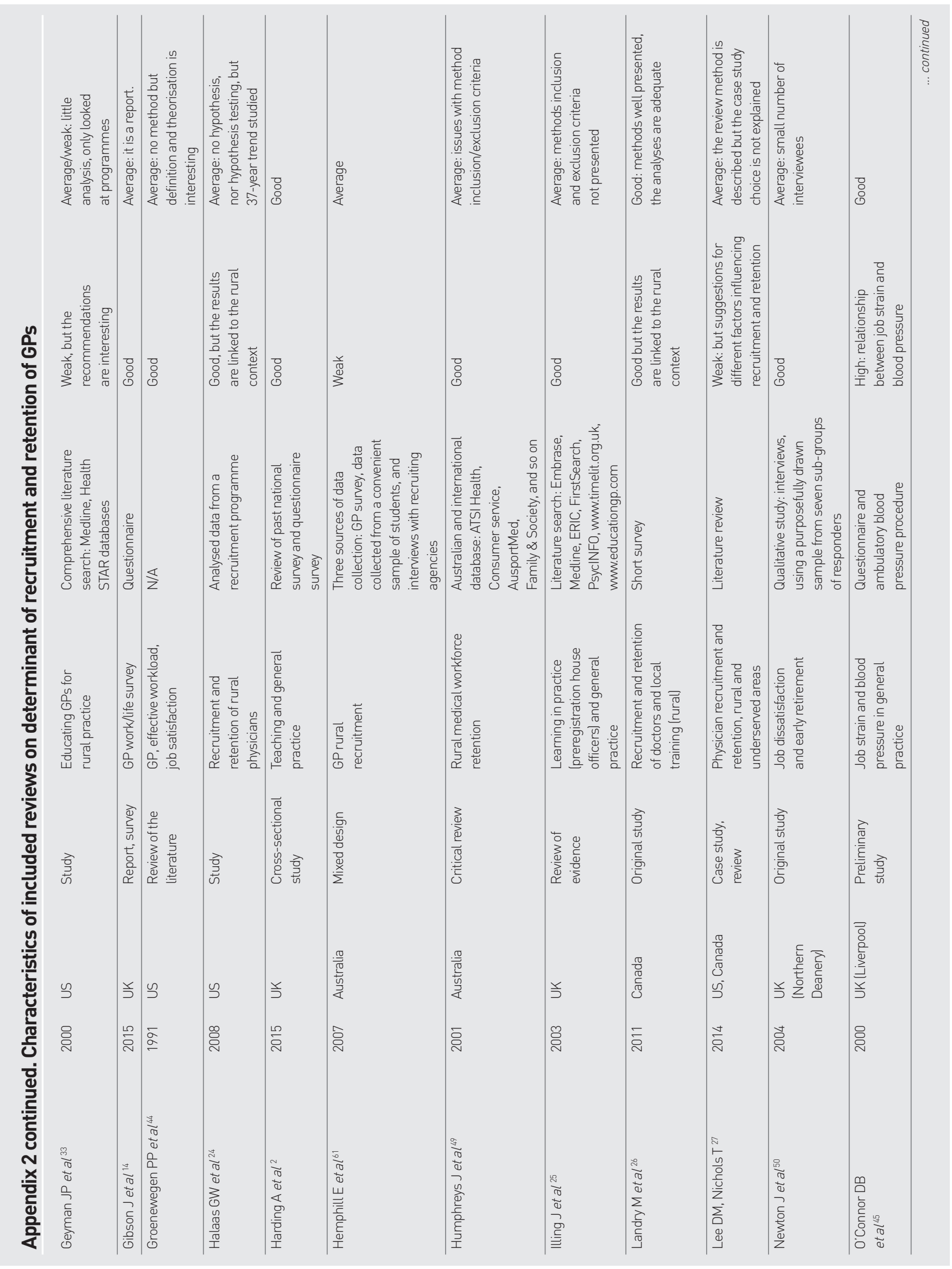




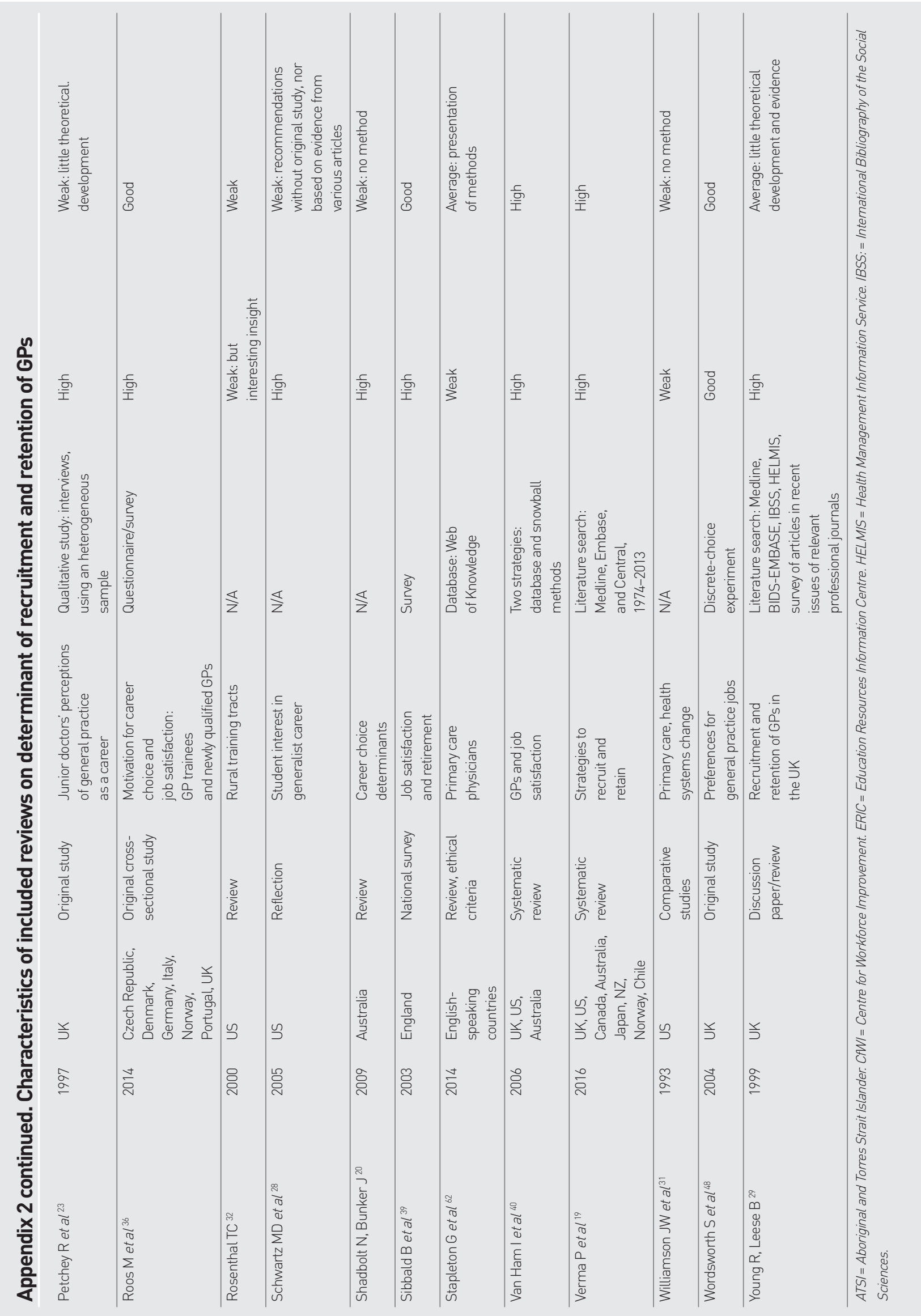

